\title{
Composición escrita, influencia mediática y ortografía. Una investigación en las aulas de Educación Primaria'
}

\author{
Written Composition, Media influence, and Spelling. \\ Research in Primary Education Classrooms \\ DOMINGO ALBARRACÍN VIVO \\ ISABEL JEREZ MARTÍNEZ \\ EDUARDO ENCABO FERNÁNDEZ \\ Universidad de Murcia \\ España \\ domingo.albarracinv@um.es \\ isabel.jerezmartinez@um.es \\ edencabo@um.es
}

(Recibido: o6-O2-20I9; aceptado: 05-o6-2019)

Resumen. El avance tecnológico está cambiando la sociedad y la escuela no puede permitirse alejarse de esta realidad. Por ello, el presente estudio analizó la influencia mediática en la composición escrita de los estudiantes de segundo tramo de Educación Primaria, estableciendo relaciones con respecto a la ortografía como parte de la competencia comunicativa lingüística del alumnado. Se llevó a cabo una intervención en dos colegios de la Región de Murcia, con un total de 180 participantes. En dichos centros el alumnado realizó una narración a partir de una imagen vinculada con la Literatura Infantil que actuaba como pretexto, posteriormente, se analizaron de manera cualitativa todas las composiciones con el programa informático Atlas. Ti y se contabilizaron las faltas de ortografía en cada una de ellas. Los principales resultados indicaron gran influencia mediática en la escritura de los estudiantes, mediante la extracción de elementos mediáticos no vinculados con el pretexto dado, en su relación ortográfica, destacó la videoconsola como el elemento que más faltas contenía en las producciones que había sido citado.

Palabras clave: TIC; literatura; alfabetización mediática; escritura.
Abstract. Technological advance is changing our society, and school cannot allow itself to move away from this reality. Therefore, the current study analyzed the media influence in the students written composition of the second stretch of Primary Education, establishing relationships with regard to spelling as part of the linguistic communicative competence of the students. An intervention was carried out in two schools of the Region of Murcia, with a total of 180 participants. In these centers, the students made a narration from an image linked to children's literature that acted as a pretext. Subsequently, all the compositions were analyzed qualitatively with the Atlas. $\mathrm{Ti}$ computer program. Furthermore the spelling mistakes in each of them were counted. The main results indicated great media influence in the writing of the students, by extracting media elements not linked under the pretext, in its grammatical relation, and highlighted the video game console as the element with more spelling mistakes in the productions that had been cited.

Keywords: ICT; literature; media literacy; writing.

\footnotetext{
I Para citar este artículo: Albarracín Vivo, Domingo; Jerez Martínez, Isabel y Encabo Fernández, Eduardo (2020). Composición escrita, influencia mediática y ortografía. Una investigación en las aulas de Educación Primaria. Alabe 21. [www.revistaalabe. com]

DOI: IO.I5645/Alabe2O2O.2I.IO
} 


\section{Introducción}

En el presente estudio encontramos tres componentes claves: una influencia mediática creciente en el alumnado por el uso de las Tecnologías de la Información y la Comunicación (TIC); la composición escrita desde una perspectiva creativa utilizando un clásico de la Literatura Infantil adaptado a modo de pretexto; y una fuerte preocupación acerca del dominio de las habilidades ortográficas en los niños y niñas. Siendo esta triple concepción la cual, propicia la investigación comparada de dichos elementos. En cuanto a las investigaciones previas que sustentan este estudio, enfocamos la concepción de la llamada Literatura Infantil desde la perspectiva de López Valero, Hernández Delgado y Jerez Martínez (2OI7) planteando la necesidad de un nuevo canon, el cual, tenga en cuenta los condicionantes sociales que afectan a dicho concepto. Otro centro de interés de nuestra investigación sitúa la influencia mediática según Pérez Rodríguez y Delgado Ponce (2OI2), desde la necesaria integración de la competencia audiovisual y la digital, coincidiendo con Jacobs (2OI4) en su baja presencia en nuestro currículo actual, contrastada con la relevancia que contiene en nuestra vida cotidiana y la de nuestro alumnado, por su concepción de nativos digitales (Prensky, 2OII). Ambos componentes (literarios y mediáticos) condicionan la comprensión del entorno inmediato de los estudiantes, pretendiendo observar su influencia en la expresión, a través de la escritura y más concretamente la ortografía, como un aspecto esencial de la Educación Primaria (Zayas, 2009).

La sociedad actual se encuentra en constante cambio, teniendo como características esenciales: la inmediatez, la necesidad de adaptación, así como la facilidad para el acceso y la publicación de la información. La educación no es ajena a esas transformaciones sociales, creando el objetivo de convertir dicha información en conocimiento. Prensky (2OII) afirma que los alumnos y alumnas de la actualidad desean el aprendizaje a través de la colaboración, el diálogo y la creatividad, en conexión con la realidad cotidiana, la cual, plantea una influencia mediática creciente, vinculada al uso de los dispositivos electrónicos para el intercambio de información, permitiendo el uso de las nuevas formas de lectura y escritura que requieren cierta alfabetización, para que los discentes se desenvuelvan de manera eficaz en su entorno, desde la conexión de los centros educativos con sus necesidades como nativos digitales. Encontrando como antecedentes a Plester y Wood (2009) en su estudio con estudiantes de edades comprendidas entre 8 y I2 años, encontraron relaciones positivas entre la experiencia con respecto a la escritura abreviada de mensajes y las puntuaciones en test estandarizados de lectura, vocabulario y normativa ortográfica. Siendo resultados sorprendentes, en comparación a la visión social que habitualmente encontramos como un aspecto contraproducente de dicha escritura. 


\section{De la composición escrita a la escritura creativa}

Las investigaciones sobre la escritura en el ámbito de la Educación Primaria han experimentado en el último siglo un desarrollo importante. En la actualidad, debido a su complejidad, no se encuentra entre los campos de investigación que más literatura en forma de estudios almacena, por tanto nos adentramos en un ámbito menos explorado que algunas de sus influencias más cercanas como la comprensión lectora. Su concepción siempre se ha encontrado ligada al objeto de estudio del momento histórico que tengamos en cuenta.

Para Salvador Mata y Arroyo González (2005) la investigación en la escritura ha desarrollado dos perspectivas diferentes a lo largo de la historia: por un lado; un enfoque que centra sus esfuerzos en el proceso para la producción, con una orientación puramente cognitiva acerca de los procesos del escrito, y por otro; una dimensión focalizada en el texto como producto con un carácter lingüístico, concretado en los aspectos formales y las estructuras del texto. Desde nuestra perspectiva para este estudio, hacemos especial hincapié en el carácter contextual de la escritura, por ello entendemos la composición escrita como una actividad que crea significados, interviniendo una serie de procesos cognitivos, mediante la interacción con el contexto para ser usados como medio de comunicación.

La escritura no debe pasar a una mera actividad de redacciones, resúmenes e intento de dominio ortográfico y gramatical para los aspectos más formales del currículo y su traslado a otras materias. Este tipo de actividades han de realizarse en el área, la problemática se plantea cuando únicamente la escritura se trabaja desde esta perspectiva. Camps (2009) afirma que la escuela debe constituir un ámbito en el cual, la escritura se use como instrumento de reflexión y comunicación para cualquier actividad. Por lo que, la escritura creativa parece idónea si la entendemos como algo que va más allá de la información, primando la calidad estética, la originalidad y la creatividad, por lo tanto, se incluye la literatura y sus géneros y subgéneros (García Carcedo, 2OII).

La forma de entender la escritura creativa para el presente estudio tiene las siguientes características: la reflexión del alumnado acerca de su realidad cotidiana; estimular sus capacidades lingüísticas; configurar un clima de pensamiento para que el alumnado sea capaz de afrontar la escritura de forma literaria y visibilizar su intertexto, con el fin de utilizarlo para sus creaciones literarias. Lo importante de todos estos antecedentes, es la forma de entender la recepción del texto por parte del lector, vinculando de manera directa la lectura y la escritura creativa. Por lo tanto desde nuestra propuesta giramos muchos aspectos de la escritura y la lectura de un texto: la importancia no recae en el texto o imagen literaria que se trabaja, sino en el alumnado; el lector ya no es un mero agente pasivo, sino que interpreta el texto a través de sus vivencias para dar vida a una nueva historia a través de su intertexto lector; cobra gran relevancia los hipertextos, ya que, el alumnado no piensa solamente en la obra del pretexto, sino que piensa en otras historias que le ocurren a personajes de diferentes obras literarias, incluso de otras tipologías. 


\section{Influencia en la escritura: elementos mediáticos y ortografía}

Los aspectos sociales que recubren la escritura no han sido un objeto de estudio explotado, la mayoría de estudios acerca de la composición escrita han centrado sus esfuerzos en lo cognitivo y lingüístico de la expresión escrita. Si reflexionamos en sus primeros antecedentes podemos observar el pensamiento de la corriente pedagógica del constructivismo con sus principales representantes: Piaget y Vygotsky, resumiendo su teoría en una sencilla frase de Kaplún (2002), no podemos comunicar sin conocer. Por ello nos preguntamos: ¿qué conocen los niños y niñas de Educación Primaria?

Responder a la pregunta anterior nos llevaría a una afirmación errónea ya que todos los niños y niñas no son atraídos por las mismas cosas, pero sí que podemos responder una cosa que comparten, la época que nos ha tocado vivir, concretada en la diversidad social-mediática que encontramos. Trasladando esta visión a la escritura, podemos afirmar siguiendo a Freinet (citado por Camps, 2003) que el lenguaje es social por naturaleza y lo vamos desarrollando mediante situaciones que implican compartir con los demás. La realidad de nuestro alumnado se encuentra estrechamente vinculada a las TIC, Según Pérez-Escoda, Castro-Zubizarreta y Fandos-Igado (2OI6) un 96.9\% del alumnado de sexto curso manifiesta en su estudio manejar más de un dispositivo tecnológico en su vida cotidiana. Siendo el ordenador, seguido por la tableta y el móvil los más utilizados.

Los elementos contextuales de la escritura van más allá de la generación de ideas para la misma, afectando también a su exigencia, el alumnado destinatario de la propuesta, utilizada diariamente los móviles, ya sean propios o de familiares, las consolas, los chats y otros tantos aparatos que pueden ser considerados mediáticos y que tienen en la escritura un medio de comunicación. La red, según Cassany (2OI2) ha tenido gran impacto en el uso de la escritura, creando géneros textuales nuevos en forma de conversación escrita (el chat), reformulando los géneros históricos como la carta y el diario personal en el correo electrónico y el blog personal. Clasificando dichos géneros provenientes del entorno digital en sincrónicos (chat, juegos de rol...) y asincrónicos (correo, foro, web, blog, wiki), dependiendo de la coincidencia en el tiempo de la interacción.

Conectando con la parte empírica del estudio, podemos afirmar que al igual que todos elementos tecnológicos no son mediáticos, todo lo mediático tampoco es tecnológico. Para nuestro estudio, hemos decidido introducir la videoconsola como elemento mediático por contener en la mayoría de las características para su consideración: espacio en línea, aplicaciones de correo electrónico y redes sociales, acceso a Internet, la posibilidad de la comunicación oral mediante micrófono, así como, la creación de comunidades de personas que interaccionan simultáneamente a través de dicho juego. El selfi también lo hemos considerado dentro de los elementos mediáticos por ser un modo de comunicar información mediante imágenes e interactuar con otras personas, además de proporcionar una influencia en el vocabulario tecnológico que utilizamos de manera cotidiana, fruto de una cultura iconográfica. 
El uso de las tecnologías como forma de comunicación, nos ha llevado a la llamada escritura ideofonemática (Cassany, 20I2) la cual desde su carácter breve y coloquial, aprovecha el valor fonético de cifras y símbolos, para alejarnos de las normas ortográficas, con fines comunicativos, los géneros textuales sincrónicos en su exigencia de escritura inmediata y no planificada ni revisada, son ejemplos claros. Todo ello, genera una visión estereotipada de dicha escritura de manera peyorativa. Sin embargo, como afirma Cassany (2OI2) "la escritura ideofonemática no es el enemigo de la escuela ni de la cultura ni el responsable directo de los problemas de corrección de los aprendices” (p. 8I). Esta situación requiere una respuesta educativa que pasa en sus primeras fases por la reflexión y tratamiento de la metodología ortográfica de manera adecuada, teniendo en cuenta el entorno digital, haciendo de lo anteriormente citado un instrumento metodológico más para los procesos de enseñanza-aprendizaje del alumnado.

La lectura y la escritura en el mundo contemporáneo se han visto modificadas por tres tipos de transformaciones: la técnica, la morfológica y la revolución de la lectura. Lo realmente interesante por su diferencia histórica con cambios anteriores, es la velocidad de dichas transformaciones y la separación del soporte de la lectura y la escritura de un contenido contextual concreto (Chartier y Scolari, 20I9). Todo ello deriva en nuevas formas de escritura y lectura que actualmente se encuentran en coexistencia con las tradicionales, los mismos autores insisten en una ecología mediática fragmentada, pasando poco tiempo en muchos medios, coincidiendo con Quiles Cabrera, Martínez Ezquerro y Palmer (20I9) en la necesidad de abordar fenómenos emergentes de texto breve, resultando muy útil para el trabajo didáctico de diversas habilidades lingüísticas.

Centrando el interés en otro aspecto relevante del estudio, analizamos la metodología usada en la formación ortográfica de los discentes, teniendo en su mayoría una visión conductista de la misma, con poca evolución desde las metodologías más tradicionales, basadas en la repetición continuada de errores. Esta investigación trata de acercar a los docentes a la realidad de la competencia léxica de su alumnado, siendo según Zayas (2009) un objetivo central en la Educación Primaria, llevando dicha ortografía no solo a la recuperación de casos particulares y aislados de faltas, sino a la detección de regularidades en las mismas, apoyándose en los vínculos ortográficos, semánticos y morfosintácticos de los grupos de palabras. Además, se ha de pretender que los estudiantes se involucren de manera activa en el aprendizaje ortográfico, desde su relevancia como componente del lenguaje escrito. Su necesaria atención docente nos lleva a la afirmación de Cassany, Luna y Sanz (I994) "La ortografía suele ser el caballo de batalla del área de Lengua durante los primeros años de enseñanza obligatoria” (p.4II). 


\section{Literatura Infantil en la escuela actual. El pretexto como recurso}

En la llamada Literatura Infantil se pueden encontrar en la actualidad aspectos distintos a los visibles hace algunas décadas, dejando más difícil su delimitación, cuando contamos con cambios en la recepción de historias, unidos al desarrollo diario de la tecnología y un público cada vez más amplio en su consumo. Por ello, en un mundo tan cambiante la Literatura Infantil se sitúa como un elemento esencial para que los estudiantes puedan comprender su realidad inmediata, siendo una tarea del docente facilitar el acceso a la misma, tratando temas de interés para los niños y niñas, en los cuales puedan identificarse fomentando el placer por la lectura (Albarracín, 2OI8). El clásico tratado en nuestra investigación puede encontrar diferentes temáticas asociadas con nuestra sociedad, ofreciendo grandes posibilidades de identificación para la escritura creativa.

López Valero, Hernández Delgado y Jerez Martínez (2OI7) afirman que la revisión del concepto de Literatura Infantil es algo complicado debido a los condicionantes sociales que genera un alumnado distinto del precedente, siendo el eclecticismo una de las características actuales y esenciales para definirla, encontrando gran diversidad de textos y combinaciones de géneros y modalidades. Por lo que conviene preguntarnos acerca de la existencia de un nuevo canon de Literatura Infantil, condicionado por los problemas sociales de nuestra época, bajo la concepción de una literatura como reflejo de la sociedad, en la cual, suman relevancia temáticas de igualdad, de alfabetización digital y mediático entre otras.

La competencia literaria, implícita en el estudio, se concibe según Martínez Ezquerro (20I6) en primer lugar, como competencia lectora que se asienta en los aprendizajes significativos y las teorías literarias, haciendo hincapié en el papel protagonista del alumnado, sustituyendo la información literaria por la educación literaria, encontrando en nuestra propuesta el análisis y la interpretación del conocimiento de la obra literaria, el disfrute de la misma vinculada con la realidad actual, así como la escritura con intención literaria, fomentando los hábitos lectores y la visión crítica de los textos.

En nuestro estudio partimos de la narración de Pinocho, ayudándonos del intertexto lector del alumnado de segundo tramo de Educación Primaria, así como de las publicaciones audiovisuales referentes a este personaje, teniendo como finalidad la creación de un nuevo cuento a partir de un pretexto dado. Por ello, requiere nuestra confianza en el conocimiento de la obra por parte de los discentes, trasladando el debate sobre qué entendemos por lectura. López Valero, Jerez Martínez y Encabo Fernández (20I6) indican que los textos no presentan en la actualidad un formato único, fluctuando mediante diferentes manifestaciones, tanto en presencia física como en entornos virtuales o formatos audiovisuales, resultando complicado para la tradición asumir naturalmente dichas interacciones bajo la denominación de lectura. Lejos de entrar en controversias, partimos de las posibilidades que ofrece el intertexto lector del alumnado y los conocimientos previos del mismo, en todas sus interacciones con dicha obra literaria. 
Coincidiendo con Quiles Cabrera, Palmer y Rosal Nadales (2015) es necesaria una visión innovadora de la enseñanza lingüística y literaria, mediante el conocimiento de los clásicos sin renunciar al placer por la lectura, siendo la actividad del estudio una muestra del enfoque anterior, ya que conectamos el clásico de la Literatura Infantil con una imagen de Pinocho acompañada de elementos mediáticos, asociándola a las vivencias del alumnado en una nueva composición escrita, a través de la escritura creativa. Para Luchetti (2OI2) el pretexto es una excusa o incentivo para la creación de otro texto. Partiendo de esta visión, el uso de imágenes que susciten la reflexión parece ser adecuado para el análisis de la escritura de textos.

\section{Alfabetización mediática}

En la actualidad, debemos concebir las TIC no solo como un recurso educativo esencial, sino también como un contenido y finalidad en sí mismo, dicha relevancia puede verse reflejada en las concreciones curriculares tanto estatales como autonómicas. Dicha perspectiva hace necesaria la incorporación de alfabetizaciones tecnológicas y mediáticas para dotar al alumnado de competencias en el uso de las TIC. Jacobs (20I4) tras un profundo análisis de nuestro currículo, afirma que nuestro sistema educativo necesita urgentemente una mayor alfabetización mediática. Por lo que, uno de los grandes retos del sistema educativo actual pasa por ofrecer una respuesta pedagógica y didáctica a dicha alfabetización.

Este panorama también se ha visto condicionado por el aumento de lo mediático en nuestra realidad cotidiana, entendiendo al alumnado como personas prosumidoras de esta cultura participativa, tanto para la recepción como para la producción de información, haciendo imprescindibles las destrezas relacionadas con los medios, las tecnologías y el tratamiento de la información, teniendo como objetivo la adquisición de autonomía en estos procesos; así como, la formación de una mente crítica que sea capaz de reflexionar la información a lo largo de su vida. Por lo tanto, la relevancia de las TIC en nuestro entorno y su influencia en la escritura queda justificada. Sin embargo, García-Ruíz, Ramírez-García y Rodríguez Rosell (20I4) afirman que "la influencia de los medios de comunicación no se ha acompasado con el fomento de la alfabetización mediática” (p. I5). Dicha competencia en alfabetización mediática, Implica grandes desafíos para la educación actual. Pérez-Escoda et al. (2OI6) advierten del peligro de una brecha digital, creada no por el uso, sino por la falta de competencia.

En esta línea, los resultados en el estudio de García-Ruiz et al. (20I6) revelan que el alumnado de Educación Primaria no ha conseguido todavía un nivel óptimo de competencia mediática, pudiendo observar entre sus mayores carencias la profundización en los lenguajes audiovisuales. Pérez Rodríguez y Delgado Ponce (2OI2) nos ofrecen los aspectos más relevantes para el desarrollo de dicha competencia mediática, sintetizados en tres ámbitos fundamentales: el ámbito del conocimiento, de la comprensión y de la expresión. 
Rovira y Llorens (20I4) establecen que la situación actual requiere distintas novedades didácticas, "no porque sea necesario para adecuarnos a las nuevas realidades digitales, sino principalmente porque nuestra perspectiva debe ser fundamental para consolidar cualquier nueva teoría de aprendizaje“ (p. 9I).

Tras observar las características y el estado de la cuestión en la alfabetización mediática, parece interesante focalizar en la vinculación con los docentes, Wilson (2OI2), indica que los programas de alfabetización mediática han estado fuera de la formación continua de maestros y maestros, de manera simultánea dichos medios de comunicación se encuentran dominando diversos aspectos de la vida cotidiana, por lo tanto, su inclusión y profundización parece inmediata, así como su línea de actuación en el futuro. Desde esta perspectiva de la formación docente se comprenden los resultados de Ramírez-García y González-Fernández (20I6), dejando ver una capacitación básica de los docentes en todas las dimensiones que integran la competencia mediática. Uno de los principios esenciales de la didáctica general para todos los niveles educativos se centra en fomentar la enseñanza a través de todo aquello que les gusta y resulta atractivo para los estudiantes, de tal manera que los aprendizajes serán cercanos produciendo gran motivación y coherencia en el trabajo realizado. Por ello, se pretende aprovechar las horas que el alumnado dedica a estos elementos mediáticos, para incentivar la producción escrita y la Literatura Infantil.

\section{Planteamiento del estudio: problema de investigación y objetivos del mismo}

Para producir una formación de calidad, se ha de conocer cómo afecta la influencia mediática en las distintas dimensiones de los estudiantes, siendo la composición escrita y la literatura unas de las más relevantes, considerándose vitales para la percepción y la expresión de la realidad. A menudo, las distintas actividades de escritura que se plantean al alumnado, se observan temáticas que no siempre están conectadas con el entorno cercano y los elementos que verdaderamente les motivan y les hacen pensar críticamente. Por ello, pretendemos ayudar a la comunidad educativa, abordando en los objetivos plateados dichos elementos mediáticos y su relación con la competencia léxica de los alumnos y alumnas.

El objetivo general del estudio se centra en conocer la influencia de la atmósfera mediática actual de los estudiantes de segundo tramo de Educación Primaria, en su composición escrita espontánea de cuentos.

Teniendo como objetivos específicos:

- Analizar los elementos mediáticos que aparecen en las producciones del alumnado sin formar parte del pretexto.

- Evaluar la ortografía de las composiciones escritas y sus relaciones con los elementos mediáticos encontrados. 


\section{Método}

La investigación tenía un diseño cualitativo basado en el análisis del contenido, proporcionado por las producciones de los participantes. Siendo alumnos y alumnas del segundo tramo de Educación Primaria $\left(4 \cdot^{\circ}, 5 \cdot^{\circ}\right.$ y $6 \cdot^{\circ}$ curso) de dos colegios ubicados en la Comarca del Noroeste de la Región de Murcia. El primer centro (colegio I), destaca por su carácter público y sus dos líneas de enseñanza; mientras que el segundo centro (colegio 2), es de tipo concertado con una línea de enseñanza, pudiendo obtener entre ambos I8o participantes, distribuidos mediante la Tabla I.

Tabla 1. Distribución de los participantes del estudio

\begin{tabular}{|ccccc|}
\hline Colegios & $\begin{array}{c}\text { Participantes } \\
\text { 4. }^{\mathbf{0}} \text { curso }\end{array}$ & $\begin{array}{c}\text { Participantes } \\
\text { 5. }^{\mathbf{0}} \text { curso }\end{array}$ & $\begin{array}{c}\text { Participantes } \\
\mathbf{6 .}^{\circ} \text { curso }\end{array}$ & $\begin{array}{c}\text { Participantes } \\
\text { segundo tramo }\end{array}$ \\
\hline Colegio 1 & 37 & 41 & 36 & 114 \\
Colegio 2 & 24 & 21 & 21 & 66 \\
Totales & 61 & 62 & 57 & 180 \\
\hline
\end{tabular}

El proceso de recogida de información se llevó a cabo estableciendo el contacto con los centros visitados, regulando nuestra presencia en los mismos y proponiendo una ubicación temporal para la realización de la actividad en todos los cursos mencionados anteriormente. La realización de la composición escrita estaba supervisada, con el fin de solucionar cualquier duda con respecto a la tarea.

La actividad, por la cual se concreta la intervención en las aulas del presente estudio, consistió en la escritura creativa de un cuento a partir de una imagen que actuaba a modo de pretexto, dicha imagen contenía a Pinocho y Geppetto, haciéndose un selfi, utilizando como mecanismo de sujeción del móvil la enorme nariz de Pinocho. Se atribuye su creación al artista Tom Ward Studio (2OI7), se puede observar que su tarea es ofrecer una visión actualizada de los clásicos Disney con elementos mediáticos (véase anexo I) y una fuerte crítica a la sociedad actual.

Con respecto al análisis de la información, distinguimos los siguientes pasos: en primer lugar, se produjo la digitalización de todas las composiciones del alumnado; en segundo lugar, se descartaron aquellas producciones que no tenían una lectura legible; en tercer lugar, se analizaron las producciones con el programa informático Atlas. Ti. 7.5 mediante un proceso de análisis de datos cualitativos, en el cual, se extraían los elementos mediáticos citados por el alumnado, así como las faltas de ortografía visibles en cada composición, realizando la lectura y análisis particular de las I8o producciones totales; por último, ayudándonos de la herramienta Atlas. Ti. 7.5 utilizamos una de sus funciones 
para exportar los datos del análisis en tablas numéricas clasificadas a Microsoft Excel, para después introducirlos en el programa informático SPSS con la finalidad de establecer estadísticos de los datos obtenidos, permitiendo resumir la información analizada en las figuras y tablas observables en los resultados.

\section{Resultados}

La presentación de los resultados responde a las Figuras y Tablas extraídas de los programas informáticos utilizados. La Figura I, nos muestra las citas realizadas por los participantes, en las cuales, nombran elementos mediáticos visibles en la imagen que actúan como pretexto, obteniendo que II5 personas mencionaron el móvil en sus producciones y 73 el selfi, siendo I8o el total de los participantes, conviene aclarar que cualquier alumno o alumna puede nombrar con su libertad creativa ambos elementos en su composición, uno de los dos o ninguno de ellos.

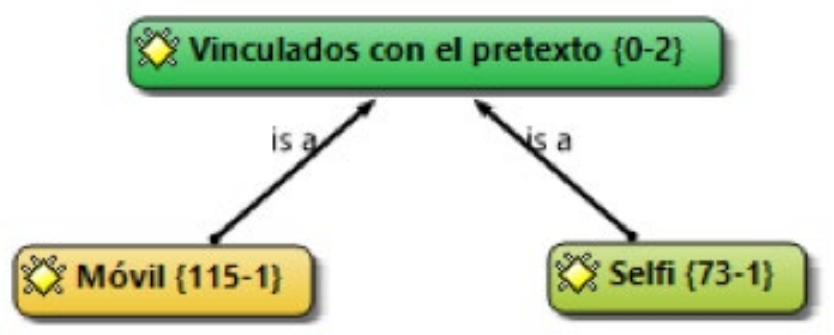

Figura 1. Elementos mediáticos citados vinculados con el pretexto.

Los elementos mediáticos citados por el alumnado que no aparecían en el pretexto, se pueden observar en la Figura 2, es relevante explicar que un cuento creado por un niño o niña puede tener más de un elemento mediático que no se vincula con el pretexto. También indicar que no se ha tenido en cuenta la repetición de dicho elemento en una misma producción, siendo los números que aparecen junto a los elementos, la cantidad de producciones que lo contienen. Por ejemplo, si un participante realiza comparaciones de distintos móviles en su producción, tan solo se aumenta una cita al grupo tipos de móviles.

Obteniendo los siguientes elementos ordenados de mayor a menor frecuencia: 33 producciones, en las cuales aparece la videoconsola; 3I, los tipos de móviles; 20, la tableta; I9, los videojuegos; I7, los ordenadores; I2, personajes y personas mediáticas; I2, televisión y Io, redes sociales; los elementos con frecuencia por debajo de io no son tenidos en cuenta para su vinculación con las faltas de ortografía (objetivo específico 2), por pertenecer a un número pequeño de producciones que no permitirían medias significativas. 


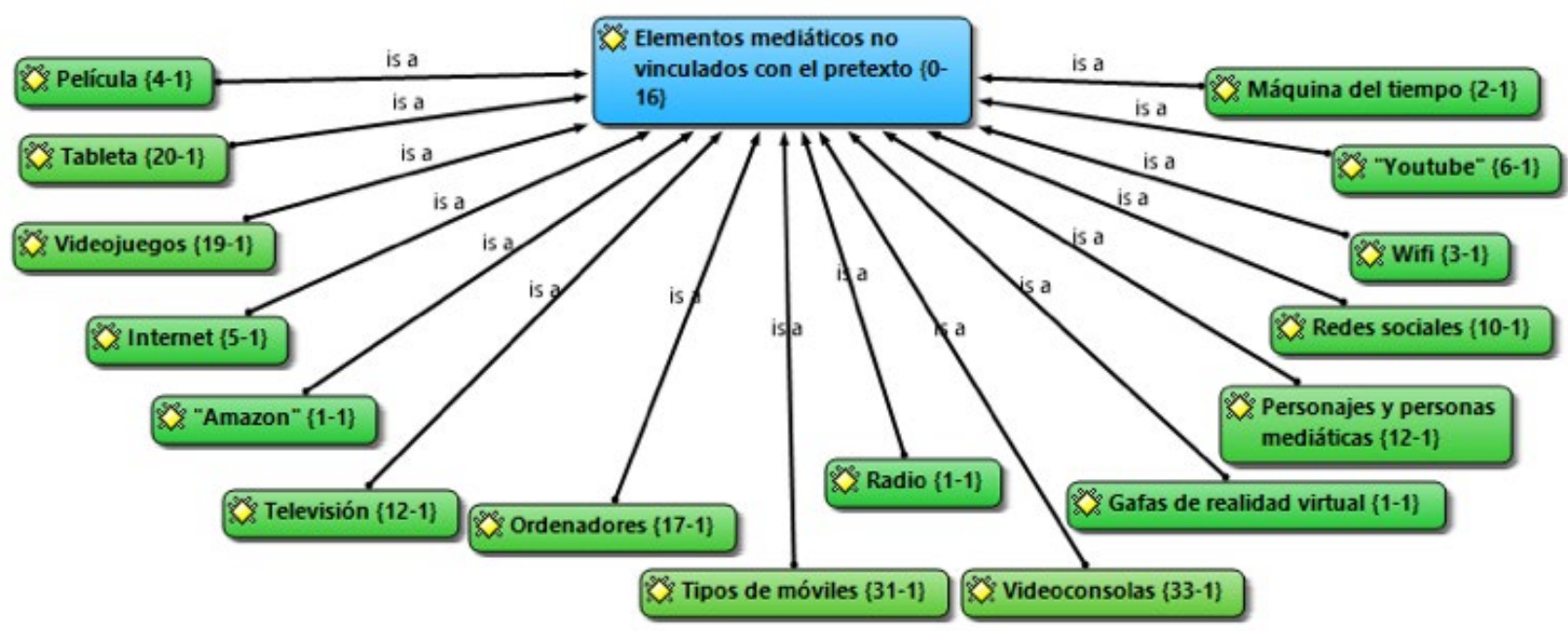

Figura 2. Elementos mediáticos citados no vinculados con el pretexto.

En la Tabla 2, se evidencia el análisis de las faltas de ortografía cometidas por los escolares de segundo tramo de Educación Primaria de los I8o participantes, divididas en cursos escolares. Para el conteo de dichas faltas, se utilizaron las siguientes normas: no se contabilizaba la repetición de la misma falta; las tildes no se tuvieron en cuenta como falta de ortografía y tampoco se concibió como faltas, los nombres de elementos inventados o palabras que son producto de la imaginación de los discentes.

Tabla 2. Distribución de faltas de ortografía según el curso educativo

\begin{tabular}{|lcccc|}
\hline & $\begin{array}{c}\text { Participantes } \\
\mathbf{4 .}^{\mathbf{0}} \text { curso }\end{array}$ & $\begin{array}{c}\text { Participantes } \\
\mathbf{5 .}^{\mathbf{0}} \text { curso }\end{array}$ & $\begin{array}{c}\text { Participantes } \\
\mathbf{6 .}^{\mathbf{0}} \text { curso }\end{array}$ & Totales \\
\hline 0 Faltas de ortografía & 3 & 6 & 11 & 20 \\
\hline 1 Falta de ortografía & 7 & 8 & 17 & 32 \\
\hline 2 Faltas de ortografía & 13 & 9 & 8 & 30 \\
\hline 3 Faltas de ortografía & 8 & 9 & 11 & 28 \\
\hline 4 Faltas de ortografía & 12 & 6 & 4 & 22 \\
\hline 5 Faltas de ortografía & 6 & 8 & 4 & 18 \\
\hline 6 Faltas de ortografía & 3 & 4 & 1 & 8 \\
\hline 7 Faltas de ortografía & 1 & 2 & 1 & 4 \\
\hline 8 Faltas de ortografía & 0 & 7 & 0 & 7 \\
\hline 9 Faltas de ortografía & 3 & 1 & 0 & 4 \\
\hline 10 Faltas de ortografía & 1 & 0 & 0 & 1 \\
\hline 11 Faltas de ortografía & 3 & 1 & 0 & 4 \\
\hline 13 Faltas de ortografía & 0 & 1 & 0 & 1 \\
\hline 14 Faltas de ortografía & 1 & 0 & 0 & 1 \\
\hline
\end{tabular}


La Tabla 3, establece las relaciones entre el número de faltas y los elementos mediáticos citados. Con el fin de facilitar la comprensión de la tabla realizamos la siguiente lectura a modo de ejemplo: siete participantes, los cuales nombraron el ordenador al menos una vez en su producción escrita, tuvieron una falta de ortografía.

Tabla 3. Distribución de faltas de ortografía según elementos mediáticos citados

\begin{tabular}{|c|c|c|c|c|c|c|c|c|c|c|c|c|c|c|}
\hline Mediático & 0 & 1 & 2 & 3 & 4 & 5 & 6 & 7 & 8 & 9 & 10 & 13 & 14 & $\begin{array}{c}\text { Citas } \\
\text { Totales }\end{array}$ \\
\hline Móvil & 15 & 21 & 17 & 20 & 18 & 6 & 5 & 1 & 5 & 4 & 1 & 1 & 1 & 115 \\
\hline Ordenadores & 0 & 7 & 0 & 4 & 4 & 0 & 1 & 0 & 0 & 1 & 0 & 0 & 0 & 17 \\
\hline $\begin{array}{l}\text { Personajes y } \\
\text { personas mediáticas }\end{array}$ & 4 & 1 & 2 & 1 & 2 & 2 & 0 & 0 & 0 & 0 & 0 & 0 & 0 & 12 \\
\hline Redes sociales & 1 & 0 & 4 & 1 & 3 & 1 & 0 & 0 & 0 & 0 & 0 & 0 & 0 & 10 \\
\hline Selfi & 13 & 13 & 15 & 11 & 8 & 7 & 0 & 0 & 1 & 2 & 1 & 0 & 1 & 72 \\
\hline Tableta & 1 & 6 & 1 & 3 & 5 & 1 & 0 & 0 & 0 & 2 & 0 & 1 & 0 & 20 \\
\hline Televisión & 2 & 1 & 2 & 2 & 2 & 2 & 1 & 0 & 0 & 0 & 0 & 0 & 0 & 12 \\
\hline Tipos de móviles & 5 & 7 & 5 & 7 & 4 & 1 & 1 & 0 & 0 & 0 & 0 & 1 & 0 & 31 \\
\hline Videoconsola & 0 & 2 & 2 & 4 & 3 & 5 & 5 & 3 & 4 & 3 & 1 & 0 & 1 & 33 \\
\hline Videojuegos & 0 & 1 & 1 & 3 & 2 & 4 & 2 & 3 & 2 & 1 & 0 & 0 & 0 & 19 \\
\hline
\end{tabular}

Con la finalidad de realizar una síntesis de los resultados obtenidos y enlazar los elementos mediáticos y las faltas de ortografía se creó la Figura 3, la cual, muestra las medias en cuanto a las faltas de ortografía, atribuidas a los distintos elementos mediáticos, así como la media general de faltas de ortografía con respecto a las ioo producciones analizadas. Además, comentar que las producciones de los alumnos y alumnas tenían una media de iıo palabras por texto escrito. 


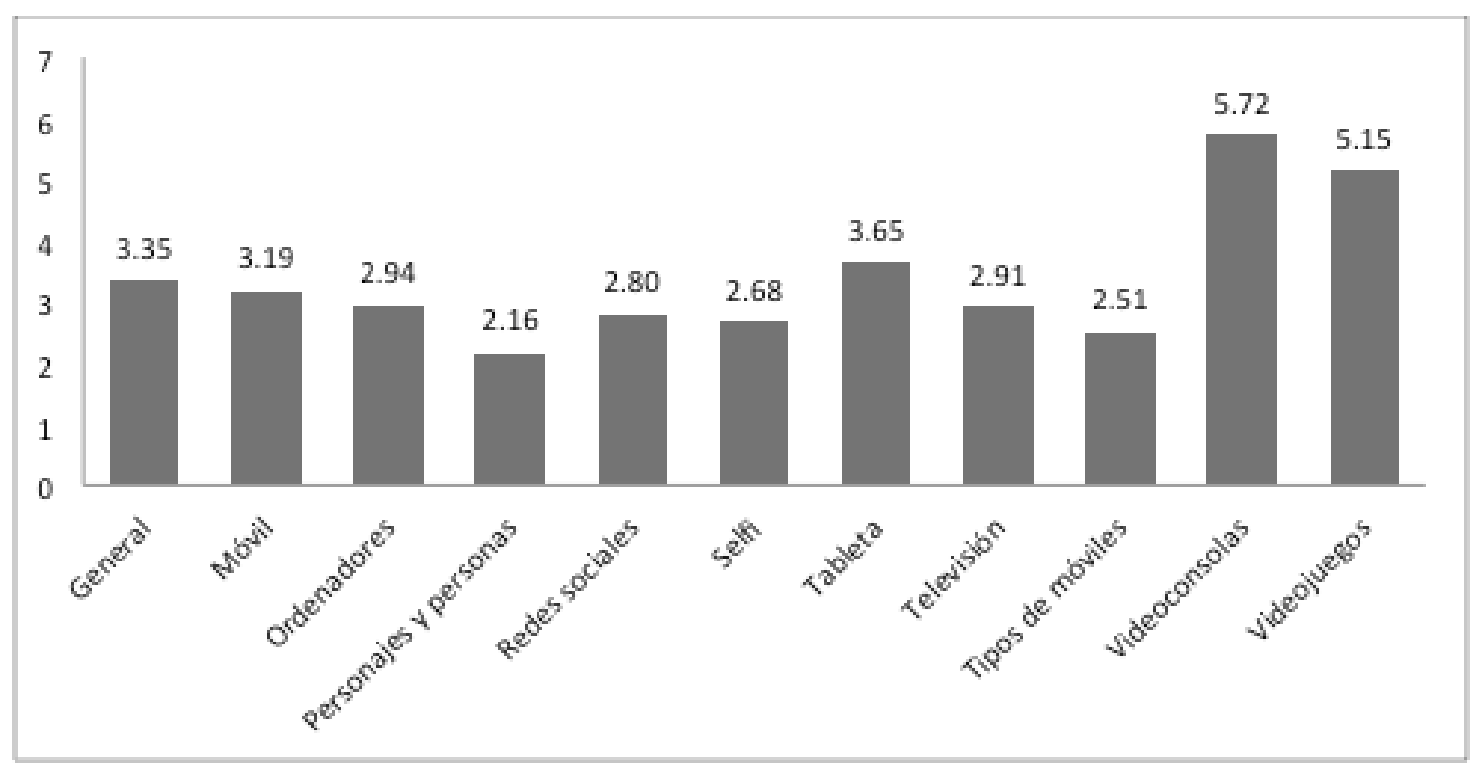

Figura 3. Medias de faltas de ortografía según elementos mediáticos citados.

\section{Discusión de los datos y conclusiones}

La discusión de los resultados mostrados en el apartado anterior, se estructura como respuesta a los objetivos específicos del estudio. Por ello, encontramos en primer lugar el análisis de los elementos mediáticos que aparecen en las producciones del alumnado sin formar parte del pretexto, implicando que los niños y niñas nombran aquello que forma parte de su vida cotidiana y sus vivencias, por ser la información qreferente a sus conocimientos previos, junto con su intertexto lector y la influencia de otras narraciones.

Resulta impactante, que el I8.33\% de las producciones realizadas por los niños y niñas de segundo tramo de Educación Primaria nombran la videoconsola en sus cuentos, el I7.22\% contienen distintas marcas y modelos de móviles, el II.II\% las tabletas, el 9.44\% los ordenadores y el $6.66 \%$ la televisión, coincidiendo con las personas y los personajes mediáticos. Estos datos representan una influencia notable en la escritura creativa de los niños y niñas. Probablemente, dichos resultados, son menos sorprendentes si aludimos el estudio de Feijoo Fernández y García González (2OI4), ya que, en un rango de edad similar al de nuestros participantes evidencian un grado alto de equipamiento tecnológico, ofreciendo cifras de un $86.4 \%$ dispone de un ordenador en su casa, un $77.3 \%$ de videoconsola y un $5^{8.5 \%}$ de teléfonos móviles. Sumando a estos porcentajes el aumento de la incidencia tecnológica desde el 2OI4 a la actualidad, podemos observar que la influencia citada en nuestro estudio no parece excesiva debido a la gran cantidad de disponibilidad de sus medios.

Tras observar la disponibilidad, pretendemos referenciar junto con Navarro, 
García, González, Contreras, y Massana (2OI2) el consumo mediático en los niños y niñas, diferenciando entre medios tradicionales y nuevos medios. La televisión es el medio tradicional más consumido, siendo en los nuevos medios las posibilidades mucho más amplias, encontrando en primer lugar, el uso del ordenador con acceso a internet; en segundo lugar, el teléfono móvil; y en tercer lugar, los videojuegos. Por tanto, este primer objetivo tiene como respuesta la gran influencia mediática que los niños y niñas tienen en su composición escrita, debido entre otros aspectos a la posesión y uso de dispositivos electrónicos y su evolución en entornos altamente digitales. Por tanto, parece imprescindible que desde las instituciones educativas, se ofrezca una respuesta a las nuevas necesidades del alumnado.

Con respecto al segundo objetivo, nuestro análisis centra su interés en la evaluación ortográfica y su asociación a elementos mediáticos concretos, esta vinculación se ha realizado mediante el conteo de las faltas ortográficas (véase Tabla 2) de los participantes del estudio y los resultados obtenidos en el objetivo anterior en el cual, se extraían los distintos elementos mediáticos citados por los participantes en sus producciones. La asociación de ambos resultados nos permite conocer la cantidad de faltas de ortografía que tienen los discentes, según los elementos mediáticos encontrados en sus composiciones escritas (véase Tabla 3), para facilitar la comprensión de estos resultados se crea la Figura 3 , indicando las medias de errores ortográficos vinculadas a los elementos mediáticos.

Los resultados obtenidos parecen probar que todavía queda mucho por hacer en la mejora de la competencia ortográfica de nuestro alumnado, ya sea por la tecnología, por los métodos de enseñanza utilizados o por sus regulaciones normativas, la media de faltas por producción de los I8o participantes es 3.35 tratándose de alumnado de segundo tramo de Educación Primaria en producciones que rondan las iıo palabras y que han sido escritas de forma creativa por dichos estudiantes es decir, con vocabulario propio. Las medias obtenidas en su asociación con los elementos mediáticos nos permite establecer dos grandes grupos: medias inferiores a la general y medias superiores a la general.

Los elementos mediáticos citados en las producciones que registran medias con menor cantidad de faltas son: el móvil, los ordenadores, los personajes y las personas mediáticas, las redes sociales, el selfi, la televisión y los tipos de móviles. Destacando la vinculación con el pretexto del móvil y el selfi, lo cual nos indica que han podido ver dichos elementos en la imagen y mencionarlos, pudiendo no formar parte de sus vivencias.

Los resultados más relevantes han sido los referidos a elementos mediáticos citados que agrupan mayor cantidad de faltas como: tabletas (3.65), videojuegos (5.5 $)$ y videoconsolas $\left(5 \cdot 7^{2}\right)$. Estas medias, posiblemente se atribuyan a usos extremadamente inmediatos de comunicación por estos medios, junto con el tiempo de uso y hábitos relacionados con los mismos, teniendo gran influencia en la escritura y haciendo necesaria una respuesta educativa acorde con dichos resultados. Lejos de culpabilizar la realidad digital que muestran los resultados, pretendemos ofrecer la visión de los videojuegos, así como del resto de elementos mediáticos más frecuentes entre el alumnado, como un potencial pedagógico o didáctico, tratando de analizar los puntos de intersección entre la experien- 
cia del alumnado con los elementos mediáticos y los contenidos de los procesos de enseñanza-aprendizaje. Con respecto al uso de videojuegos, según Gros (2008), el alumnado actual se alfabetiza digitalmente con ellos, lo cual implica la adquisición de competencias distintas a generaciones anteriores, requiriendo unos aprendizajes diferentes para manejarse en la sociedad digital.

A modo de conclusión, nuestro alumnado se encuentra inserto en un contexto de recepción y producción de información, en este nuevo paradigma mediático tiene cabida el concepto de cultura participativa, tras la convergencia entre medios tradicionales y nuevos medios de comunicación. Desde la escuela se debe prestar especial atención a la educación en elementos mediáticos tradicionales como el periódico en papel o las cartas, ya que el alto consumo citado de los elementos tecnológicos implica el detrimento de los clásicos.

También se ha de mencionar que no tratamos de ofrecer respuesta a las distancias teóricas encontradas en referencia al posible empobrecimiento ortográfico de los niños y niñas con respecto a las tecnologías, ya que a nuestros discentes les ha tocado crecer entre pantallas, por tanto, establecer estudios con variables que no tengan en cuenta la tecnología en las aulas sería alejarnos de su realidad cotidiana. Centrando los intereses en futuras investigaciones referidas a propuestas didácticas para trabajar el uso ortográfico y su vinculación con los elementos mediáticos más usados, teniendo como referencia los principales hallazgos del presente estudio, los cuales sitúan a las videoconsolas y los videojuegos como los elementos mediáticos que poseen mayor número de faltas de ortografía en las producciones que han sido citados. 


\section{Referencias}

- Albarracín Vivo, D. (2OI8). Análisis de una intervención didáctica a través de las fábulas en cuarto curso de Educación Primaria. En Alonso, J.C., Nortes, R., Albaladejo, S. y Orcajada, N. (Eds), Investigación educativa en las aulas de Primaria (pp. 36-51). Murcia: Editum.

- Arroyo González, R. y Salvador Mata, F. (2005). El proceso de planificación en la composición escrita de alumnos de educación primaria. Revista de educación, 336, 353-376.

- Camps, A. (2003). Texto, proceso, contexto, actividad discursiva: puntos de vista diversos sobre la actividad de aprender y de enseñar a escribir. Barcelona: Graó.

- Camps, A. (2009). Siete principios en que basar la enseñanza de la escritura en Primaria y Secundaria. Leer.es, I-6.

- Cassany, D., Luna, M. y Sanz, G. (I994). Enseñar lengua. Barcelona: Graó.

- Cassany, D. (2012). En_línea. Leery escribir en la red. Barcelona: Anagrama.

- Chartier, R. y Scolari, C. (20I9). Cultura escrita y textos en red. Barcelona: Gedisa.

- Feijoo Fernández, B. y García González, A. (2OI4). La confluencia mediática en la vida de los niños. El consumo de televisión e internet por parte de los menores gallegos de iı y i2 años. Sphera Publica, 2, (I4), 6I-79.

- García Carcedo, P. (2OII). Escritura creativa y competencia literaria. Lenguaje y Textos, 33, 49-59. Recuperado de: http://www.sedll.org/sites/default/files/journal/escritura_ creativa_y_competencia_literaria._garcia_p.pdf

- García-Ruiz, R., Ramírez-García, A. y Rodríguez-Rosell, M.M. (2Or4). Educación en alfabetización mediática para una nueva ciudadanía prosumidora. Comunicar, 22(43), I5-23. doi: http://dx.doi.org/IO.3916/C43-20I4-O.

- Gros, B. (2008). Videojuegos y aprendizaje. Barcelona: Graó.

- Jacobs, H.H. (20I4). Currículum 21: Essential Education for a Changing World. Madrid: Narcea.

- Kaplún, M. (2002). Una pedagogía de la comunicación. La Habana: Caminos.

- López Valero, A., Hernández Delgado, L. y Jerez Martínez, I. (2OI7). El encabalgamiento escolar y cultural de la Literatura Infantil. Alabe, I6, I-I6. doi: Io.I5645/Alabe2OI7.I6.I.

- López Valero, A., Jerez Martínez, I. y Encabo Fernández, E. (20I6). Aproximación educativa ante los nuevos formatos narrativos. Revista chilena de literatura, 94, 197-2I4. Recuperado de https://scielo.conicyt.cl/pdf/rchilite/ng4/artio.pdf 
- Luchetti, E. (2OI2). El texto como pretexto: Una propuesta de lectura creadora. Lectura y vida, $2,35^{-3} 6$.

- Martínez Ezquerro, A. (20i6). El método de cooperación interpretativa como estrategia lectora. Alabe, I4, I-20. doi: Io.I5645/Alabe2or6.I4.I.

- Navarro, H., García, I., González, Z., Contreras, R., y Massana, E. (2012). El consumo multipantalla. Estudio sobre el uso de medios tradicionales y nuevos por parte de niños, jóvenes, adultos y personas mayores en Cataluña. Quaderns Del CAC, I5(I), 9I-IOO.

- Pérez-Escoda, A., Castro-Zubizarreta, A. y Fandos-Igado, M. (20I6). La competencia digital de la Generación Z: claves para su introducción curricular en la Educación Primaria. Comunicar, 24(49), 7I-8o. doi: http://dx.doi.org/IO.39I6/C49-2OI6-O7.

- Pérez Rodríguez, M. A., y Delgado Ponce, Á. (2OI2). De la competencia digital y audiovisual a la competencia mediática: dimensiones e indicadores. Comunicar, 2O(39), 25-34. doi: https://doi.org/IO.39I6/C39-2OI2-O2-O2.

- Plester, B. y Wood, C. (2009). Exploring relationships between traditional and new media literacies: British preteen texters at school. Journal of Computer-Mediated Communication, I4, IIO8-II29. doi:IO.IIII/j.IO83-6IOI.2O09.0I483.X.

- Prensky, M. (2OII). Enseñar a nativos digütales. Madrid: SM.

- Quiles Cabrera, M. C., Martínez Ezquerro, A. M., y Palmer, Í. (2Or9). Enredos de palabras: gramática y uso de la lengua en nuevos espacios de comunicación. Barcelona: Graó.

- Quiles Cabrera, M. C., Palmer, Í. y Rosal Nadales, M. (20I5). Hablar, leery escribir. Eldescubrimiento de las palabras y la educación lingüistica y literaria. Madrid: Visor.

- Ramírez-García, A., y González-Fernández, N. (20i6). Competencia mediática del profesorado y del alumnado de educación obligatoria en España. Comunicar, I4(49), 49-58. https://doi.org/IO.3916/C49-20I6-05.

- Rovira, J. y Llorens, R. F. (20I4). Nuevos horizontes en la didáctica de la de la lengua y la literatura: hacia una educación literaria y digital. En Cleger, O., De Amo, J.M. (Eds), La educación literaria y la e-literatura desde la minificción. Enfoques hipertextuales para el aula, (pp. 76-93). Barcelona: Universitat de Barcelona.

- Tom Ward Studio. (2OI7). emailevans.co.uk. Recuperado de http://www.tomwardstudio. $\mathrm{com} /$.

- Zayas, F. (2009). Ortografía y aprendizaje de la lengua escrita. Aula de innovación educativa, 56, 9-I5. Recuperado de http://www.fzayas.com/portfolio/ortografia-y-aprendizajede-la-lengua-escrita/. 


\title{
Anexo: I. Actividad realizada por los participantes en el estudio
}

\author{
Curøo: \\ Niño $\square$ Niña $\square$
}

Crea una historia a partir de lo que ves en la imagen

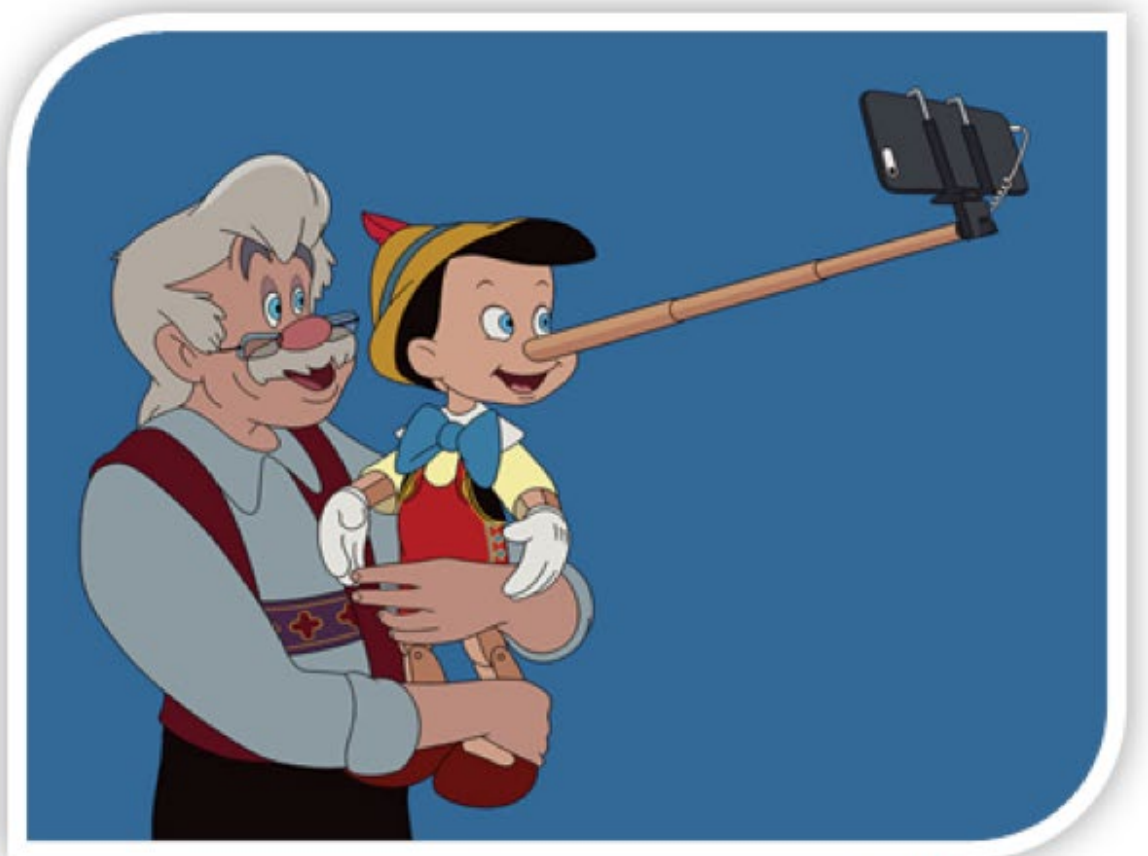

(Tom Want Studio, 2017)

Título: 